\title{
8
}

\section{CAPITAL PANDÊMICO E ENSINO REMOTO: O POSICIONAMENTO POLÍTICO DO SERVIÇO SOCIAL}

\author{
Pandemic capital and remote education: the political positioning of social work
}

\author{
Laryssa Danielly Silva Fernandes* \\ https://orcid.org/0000-0003-2492-6599 \\ Marileia Goin** \\ https://orcid.org/0000-0003-4859-3098 \\ Islânia Lima da Rocha*** \\ https://orcid.org/0000-0002-1079-4292
}

\section{RESUMO}

O artigo analisa o chamado capital pandêmico e seus impactos para as políticas sociais, situando a precarização dos serviços prestados à classe trabalhadora, dentre eles a imposição do ensino remoto como forma de atender às necessidades do mercado. Pretende-se situar como esse modelo de ensino vem impactando no processo de construção e de acesso ao conhecimento, ao pontuar seus fatores e limites para docentes, discentes e para a educação em geral. $O$ estudo se fez a partir de revisão bibliográfica e documental, tomando-se como referência a produção de autores marxistas sobre o contexto de crise acirrado pela pandemia, além do posicionamento político das entidades representativas da categoria, que se manifestam diante de mais uma estratégia de fragilização da formação profissional de assistentes sociais. Em tempos de acirramento das expressões da questão social e de regressão dos direitos, intensificados pela política de morte do governo federal, o Serviço Social faz um chamado à resistência diante da ampliação do projeto privatista de educação e do aprofundamento das desigualdades sociais.

\section{PALAVRAS-CHAVE}

Capital pandêmico. Ensino remoto. Serviço Social. Entidades organizativas.

\footnotetext{
*Assistente Social. Mestranda do Programa de Pós-Graduação em Política Social da Universidade de Brasília (SER/UnB, Brasília (DF), Brasil)). Campus Universitário Darcy Ribeiro, Brasília (DF), CEP 70910-900. E-mail: laryssadsfernandes@outlook.com.

${ }^{* *}$ Assistente Social. Doutora em Serviço Social. Professora da graduação e da pós-graduação do Departamento de Serviço Social da Universidade de Brasília. (UnB, Brasília (DF), Brasil). Campus Universitário Darcy Ribeiro, Brasília-DF | CEP 70910-900. E-mail: mari.goin@hotmail.com.

*** Assistente social. Doutoranda do Programa de Pós-graduação em Serviço Social da Faculdade de Serviço Social (FSSO/UFAL). Professora do curso de Serviço Social da Faculdade de Serviço Social da Universidade Federal de Alagoas. (FSSO/UFAL, Maceió, Brasil). Av. Lourival Melo Mota, s/no., Tabuleiro do Martins, Maceió (AL), CEP.: 57072-900. E-mail: is_rocha@hotmail.com.
}

\section{DOI 10.22422/temporalis.2019v19n37p87-101} Commons Atribuição 4.0 Internacional (https://creativecommons.org/licenses/by/4.o/deed.pt_BR), que permite copiar e redistribuir o material em qualquer suporte ou formato, bem como adaptar, transformar e criar a partir deste material para qualquer fim, mesmo que comercial. O licenciante não pode revogar estes direitos desde que você respeite os termos da licença.

Temporalis, Brasília (DF), ano 21, n. 41, p. 87-101, jan./jun. 2021. | ISSN 2238-1856 


\begin{abstract}
The article analyzes the so-called pandemic capital and its impacts on social policies, placing the precariousness of services provided to the working class, including the imposition of remote education as a way to meet the needs of the market. It is intended to situate how this teaching model has been impacting on the process of construction and access to knowledge, by punctuating its factors and limits for teachers, students and for education in general. The study was based on a bibliographic and documentary review, taking as a reference the production of Marxist authors on the context of crisis worsened by the pandemic. weakening of professional training for social workers. In times of worsening expressions of the social issue and regression of rights, intensified by the federal government's death policy, Social Work calls for resistance in the face of the expansion of the privatist education project and the deepening of social inequalities.
\end{abstract}

\title{
KEYWORDS
}

Pandemic capital. Remote education. Social Work. Organizational entities.

Submetido em: 22/3/2021.

Aceito em: 7/6/2021.

\section{INTRODUÇÃO}

$\mathrm{D}$ iante do cenário de retrocessos estruturantes no âmbito dos direitos e das políticas sociais que se adensaram no contexto da pandemia da Covid-19, revela-se fundamental apreender como a crise sanitária e a implementação de medidas ultraliberais vêm aprofundando a desigualdade social, no Brasil. Assim, neste estudo buscou-se analisar os rebatimentos do capital pandêmico nas políticas sociais, bem como investigar os impactos do ensino remoto para a educação e para a formação profissional em Serviço Social.

Neste sentido, o artigo se propõe a (1) discutir o contexto de capital pandêmico ${ }^{1}$ e suas implicações para a (re)produção das relações sociais na sociedade capitalista, além dos impactos para as políticas sociais no Brasil; (2) apreender os impactos do ensino remoto para o acesso e a construção do conhecimento no âmbito da educação; e (3) sintonizar o posicionamento das entidades representativas do Serviço Social acerca do ensino remoto e as ameaças à formação profissional.

Nesse aspecto, com objetivo de assegurar a cientificidade do trabalho, evitando abordagens unilaterais e a-históricas, optou-se pela perspectiva materialista históricodialética, estabelecendo diálogo com autores da tradição marxista, o qual, dada a dinâmica da sociedade e as incertezas que o contexto reflete - conforme será evidenciado nas páginas que seguem -, não esgota a necessidade de seu debate contínuo na cena hodierna.

\section{PANDEMIA DA COVID-19²: ENTRE O CONTEXTO DE CAPITAL PANDÊMICO E O GOVERNO BRASILEIRO}

O contexto econômico-social mundial antes da propagação do vírus SARS-COV-2, em Wuhan, na China, denotava um cenário mundial de altos índices de desemprego,

\footnotetext{
${ }^{1}$ Termo utilizado por Antunes em seu livro Coronavírus, o trabalho sob fogo cruzado (2020), o qual foi adotado neste estudo porque traduz a conexão entre o surgimento do Coronavírus e o modo de produção capitalista, marcado pela sua crise estrutural desde 1970 e pelo seu caráter discriminatório das classes sociais.

${ }^{2}$ Vírus SARS-COV-2 ou popularmente conhecido como Coronavírus.
}

Temporalis, Brasília (DF), ano 21, n. 41, p. 87-101, jan./jun. 2021. | ISSN 2238-1856 
trabalhos informais e a generalizada miserabilidade da classe trabalhadora. Antunes (2020) destaca dados da Organização Internacional do Trabalho (OIT), os quais evidenciam como esta realidade se intensifica após a pandemia, pois no segundo trimestre de 2020 se fazia uma projeção de perda de 195 milhões de empregos - 1,6 bilhões de pessoas já viviam na informalidade.

No que se refere à conjuntura brasileira antes da pandemia, Antunes (2020) explica que

[...] mais de $40 \%$ da classe trabalhadora brasileira encontrava-se na informalidade ao final de 2019. No mesmo período, uma massa em constante expansão de mais de cinco milhões de trabalhadores/as experimentava as condições de uberização do trabalho, propiciadas por aplicativos e plataformas digitais, o que até recentemente era saudado como parte do 'maravilhoso' mundo do trabalho digital, com suas 'novas modalidades' de trabalho on-line que felicitava os novos 'empreendedores' (ANTUNES, 2020, p. 7).

A inter-relação entre a crise econômica e a pandemia do coronavírus têm gerado impactos profundos àqueles/as que dependem de seu trabalho para sobreviver, isso porque as condições de precarização, superexploração do trabalho, terceirização, subempregos e trabalho intermitente tendem a ser mais perversos no contexto da crise sanitária. Antunes (2020, p.07-08) afirma ainda que o desenvolvimento econômico do capitalismo "[...] não possui limites para a sua expansão [...]" (ANTUNES, 2020, p. 8) e "[...] sua resultante é uma acentuada destrutividade" (ANTUNES, 2020, p. 8).

Esse processo de desenvolvimento do capitalismo envolve, por um lado, a produção, a valorização do capital, a mundialização e a financeirização, que resultam na concentração da riqueza mundial por meio do universo corporativo; e por outro, há a proliferação do "[...] trabalho análogo à escravidão, a superexploração (por exemplo, dos/as imigrantes), generalização da terceirização em todas as esferas laborativas, informalidade e intermitência [...]" (ANTUNES, 2020, p. 11), configurando as decorrências devastadoras deste modo de produção ${ }^{3}$. O autor complementa afirmando que "[...] é no solo da crise estrutural do capital que a pandemia vem se proliferando intensamente e, em poucos meses, já levou à morte milhares de pessoas em todo o mundo, além de desempregar milhões de trabalhadores e trabalhadoras"" (ANTUNES, 2020, p. 13).

David Harvey (2020), em seu artigo Política anticapitalista em tempos de Covid-195 afirma que o modelo de acumulação capitalista já se encontrava em declínio antes mesmo da pandemia - cuja referência é feita à crise estrutural do capital - uma vez que "[...] este modelo neoliberal assenta cada vez mais no capital fictício e numa vasta expansão na

\footnotetext{
3 'Desemprego monumental, destruição ambiental, 'mercadorização' da vida e o incentivo diário a novas guerras e conflitos armados [...]" (ANTUNES, 2020, p. 10), além da "Uberização do trabalho, distintos modos de ser da informalidade, precarização ilimitada, desemprego estrutural exacerbado, trabalhos intermitentes em proliferação, acidentes, assédios, mortes e suicídios: eis o mundo do trabalho que se expande e se desenvolve na era informacional, das plataformas digitais e dos aplicativos" (ANTUNES, 2020, p. 10-11).

${ }^{4}$ Os dados mais recentes publicados pelo IBGE somam-se 14,8 milhões de desempregados no Brasil. A pesquisa realizada pela Pnad revela uma taxa de $14,7 \%$ de desempregados no primeiro trimestre de 2021 (IBGE, s.d.).

${ }^{5}$ Publicado em 2020 pela editora Terra sem Amos: Coronavírus e a luta de classes.
}

Temporalis, Brasília (DF), ano 21, n. 41, p. 87-101, jan./jun. 2021. | ISSN 2238-1856 
oferta de dinheiro e na criação de dívida" (HARVEY, 2020, p. 14). Nesse sentido, complementa:

[...] como poderia o modelo econômico dominante, com sua legitimidade reduzida e sua saúde delicada, absorver e sobreviver aos impactos inevitáveis do que poderia se tornar uma pandemia? A resposta dependia muito de quanto tempo a ruptura poderia durar e se espalhar, pois, como Marx apontou, a desvalorização não ocorre porque as mercadorias não podem ser vendidas, mas porque não podem ser vendidas a tempo (HARVEY, 2020, p. 14-15).

Nesta esteira, a disseminação da Covid-19 mantém relação com a probabilidade de mutações do vírus, favorecido por condições ambientais que permitem seu fortalecimento, e com as condições factíveis à sua alta transmissibilidade, a exemplo de lugares com grande densidade populacional. Ademais, como evidencia Harvey (2020), "[...] o impacto econômico e demográfico da disseminação do vírus depende de fissuras e vulnerabilidades preexistentes no modelo econômico hegemônico" (HARVEY, 2020, p. 1516).

Não há dúvidas que a pandemia afeta diretamente a economia ${ }^{6}$ e, principalmente, a dos países com predominância liberal e privatista, ao consolidar ainda mais a premissa do Estado mínimo para o social e máximo para o capital. Este contexto ultra neoliberal, com restrição de aplicação de recursos especialmente para a área social, ausência de investimentos nas políticas sociais (especialmente na política de saúde), acarreta uma crise sanitária sem precedentes em terras brasileiras - vale lembrar que o desfinanciamento da saúde, em destaque para o Sistema Único de Saúde (SUS), agrava os impactos da pandemia no Brasil.

Harvey (2020) ressalta que

[...] quarenta anos de neoliberalismo na América do Norte e do Sul e na Europa tinham deixado o público totalmente exposto e mal preparado para enfrentar uma crise de saúde pública deste tipo. [...] Em muitas partes do suposto mundo 'civilizado', governos locais e autoridades regionais/estatais, que invariavelmente formam a linha de frente da defesa em emergências de saúde pública e segurança deste tipo, tinham sido privados de financiamento graças a uma política de austeridade destinada a financiar cortes fiscais e subsídios às corporações e aos ricos (HARVEY, 2020, p. 17).

A crise pandêmica atinge diretamente a classe trabalhadora, ao implicar na lógica do que Harvey (2020) define como "pandemia de classe". Essa classe, além de correr o maior risco de contrair o vírus, corre também o maior risco de perder seu emprego devido à crise econômica. O autor destaca que o "[...] progresso da Covid-19 exibe todas as características de uma pandemia de classe, gênero e de raça [...]” (HARVEY, 2020, p. 21), pois observa-se a dependência das tecnologias de informação e comunicação (TICS) 7 e a redução do trabalho vivo, acarretando desemprego, subemprego, trabalhos informais e terceirização de serviços.

É nesse contexto que se instaura o capital pandêmico, por meio da "[...] imbricação trágica entre sistema de metabolismo antissocial do capital, crise estrutural e explosão do

\footnotetext{
${ }^{6}$ Harvey (2020, p. 17) explica que "[...] o crash da bolsa de valores que começou em meados de fevereiro oscilou um pouco, mas em meados de março levou a uma desvalorização líquida de quase $30 \%$ nas bolsas de valores em todo o mundo".

7 Durante a pandemia houve um boom para as grandes corporações: Amazon, Google Meet, Microsoft etc.
}

Temporalis, Brasília (DF), ano 21, n. 41, p. 87-101, jan./jun. 2021. | ISSN 2238-1856 
coronavírus" (ANTUNES, 2020, p. 14). Na mesma esteira de Harvey acerca do caráter de classe, raça e gênero que a pandemia apresentou, o autor demonstra que o capital pandêmico possui caráter discriminatório em relação às classes sociais, em uma lógica que as mulheres trabalhadoras sofrem mais que os homens, em um contexto de "divisão sociossexual e racial do trabalho" 8 .

Deste modo, a pandemia atinge profundamente a classe trabalhadora, uma vez que ela depende diretamente da realização do seu trabalho, isto é, da venda do seu único bem, a sua força de trabalho, para garantir a sua reprodução. Trata-se de uma classe desprovida de proteção social e que se encontra em intenso fogo cruzado, sob a mortalidade do vírus e a letalidade do capitalismo (ANTUNES, 2020), que no Brasil se intensifica pelos rumos que o governo Bolsonaro tem dado à questão, numa clara tendência de ampliação da miserabilidade da classe trabalhadora?.

Frente a incapacidade do atual governo gerir a crise, Dino (2020) destaca a falta de "[...] insumos de saúde, respiradores, kits de testagem, que evidencia dificuldades administrativas causadas pela premissa política de indiferença quanto a tragédia" (DINO, 2020, p. 66). Soma-se a isso o declarado negacionismo ${ }^{10}$ do Presidente da República, que resultou (e ainda resulta) em um posicionamento tardio as medidas econômicas destinadas às famílias, e

[...] impulsiona-se uma verdadeira onda regressiva que impõe um retrocesso civilizatório pautado na perseguição, em fake news e no autoritarismo, que recuperam elementos da particularidade social brasileira, como o colonialismo, a escravização, a europeização cultural, o machismo, o sexismo e as opressões (FARAGE, 2021, p. 53).

Nesse contexto, o Estado burguês reverbera sua posição no âmbito da sociedade de classes, adensado pela Emenda Constitucional (EC) $\mathrm{N}^{0} 95^{11}$ que continua vigente na conjuntura de crise sanitária do país. A Emenda impõe "[...] constrangimentos sucessivos e progressivos ao orçamento da administração federal, colocando em xeque, antes de tudo, as despesas discricionárias, dinâmica que força, em seguida, o encolhimento das despesas obrigatórias" (GIOLO, 2020, p. 24). Com os investimentos congelados por 20

\footnotetext{
${ }^{8}$ Para o autor, em sua nova morfologia, a divisão sociossexual e racial do trabalho revela que "[...] as mulheres trabalhadoras brancas sofrem mais que os homens brancos, enquanto as trabalhadoras negras são ainda mais penalizadas que as brancas" (ANTUNES, 2020, p. 14).

${ }_{9}^{9}$ Alguns elementos que explicitam a intensificação da miserabilidade da classe trabalhadora: desmonte de direitos em um contexto de contrarreformas; ausência de políticas sociais efetivas, ao observar-se uma lógica de políticas cada vez mais fragilizadas e fragmentadas; privatização dos serviços; alto índice de desemprego; condições de trabalho instáveis e precarizados; ausência de políticas efetivas para a proteção sanitária da classe trabalhadora; inexistência de políticas de médio e longo prazo que garantam a sua sobrevivência; dentre outros.

10 Bolsonaro subestima a tragédia que o coronavírus vem causando em nível mundial, caracterizando-a como uma gripezinha. Para Löwy (2020, p. 148-149, grifo do autor), é “[...] uma definição que merece entrar nos anais, não da medicina, mas da loucura política. Mas esta loucura tem sua lógica, que é a do neofascismo". De acordo com o autor, Bolsonaro revela traços do social-darwinismo atrelado a sobrevivência dos mais pobres e o obscurantismo que está relacionado com o menosprezo pela ciência.

11 Trata do congelamento dos gastos públicos, instituindo um novo regime fiscal. Foi aprovada em 15 de dezembro de 2016, no governo Temer, e até hoje tem causado imensos rebatimentos à classe trabalhadora.
}

Temporalis, Brasília (DF), ano 21, n. 41, p. 87-101, jan./jun. 2021. | ISSN 2238-1856 
anos, as políticas sociais sofrem os rebatimentos dessa crise e o país ${ }^{12}$ fica à mercê de um governo neofascista ${ }^{13}$, em um contexto frágil para a organização da classe trabalhadora. Michael Löwy (2020), ao explicitar como se deu o avanço dos governos neofascistas, aponta que o governo brasileiro se insere nessa lógica.

Não é a repetição do fascismo dos anos 1930: é um fenômeno novo, com características do século 21. Por exemplo, não toma a forma de uma ditadura policial, mas respeita algumas formas democráticas: eleições, pluralismo partidário, liberdade de imprensa, existência de um Parlamento, etc. Naturalmente, trata, na medida do possível, de limitar ao máximo estas liberdades democráticas, com medidas autoritárias e repressivas. Tampouco se apoia em tropas de choque armadas, como o eram as SA alemãs ou o Fascio italiano. [...] Enquanto que o fascismo clássico propugnava a intervenção massiva do Estado na economia, o neofascismo de Bolsonaro é totalmente identificado com o neoliberalismo, e tem por objetivo impor uma politica socioeconômica favorável a oligarquia, sem nenhuma das pretensões 'sociais' do fascismo antigo (LÖWY, 2020, p. 148).

Uma das decorrências mais brutais do modelo neoliberal é o desmantelamento das políticas sociais, em que serviços públicos fundamentais ${ }^{14}$, a exemplo do Sistema Único de Saúde (SUS) e do ensino público precisam ser defendidos cotidianamente contra a privatização ${ }^{15}$. O corte de verbas para a saúde e para a educação, que vem se ampliando desde o governo Lula, é uma das principais formas de abertura para a iniciativa privada e

\footnotetext{
${ }^{12}$ Dino (2020) ressalta que esses impactos são sentidos, principalmente, em "[...] regiões historicamente mais empobrecidas, em face das desigualdades sociais e regionais" (DINO, 2020, p. 67).

${ }^{13}$ Michael Löwy caracteriza-o como um fenômeno novo, relacionado a ascensão de governos de extrema direita, autoritários e reacionários.

${ }^{14}$ No caso da política de saúde, esta foi impactada diretamente pela sobrecarga de seus serviços diante da necessidade de atendimento à população infectada, além do enfrentamento à lógica de privatização e do seu estrangulamento pelas medidas de ajuste fiscal. A política de assistência social, por sua vez, foi afetada pela limitação dos seus recursos financeiros para o atendimento aos mais pobres, com uma lógica residual, fragmentada e voltada para a transferência de renda, como é o caso do auxílio emergencial, inicialmente pago no valor de $\mathrm{R} \$ 600,00$ - vale lembrar que o auxílio emergencial pago em 2020 dividiu-se em dois momentos: as cinco primeiras parcelas pagas no valor de $\mathrm{R} \$ 600,00$ e outras quatro parcelas no valor de $\mathrm{R} \$ 300,00$. Para ter acesso ao pagamento, o governo federal instituiu critérios, como: renda familiar entre meio e três salários-mínimos, não cumulativo com outros benefícios, exceto o bolsa família; pessoas que estejam desempregadas ou que sejam microempreendedores individuais, contribuinte individual da previdência social e trabalhador informal. Atualmente, o Congresso Nacional promulgou a PEC Emergencial (PEC 186/19), que permite a volta do auxílio emergencial em 2021, não estando consensuado o valor o debate (poderá ser de $\mathrm{R} \$ 175,00$ a $\mathrm{R} \$ 375,00$ por quatro meses, totalizando um gasto total de $\mathrm{R} \$ 44$ bilhões) (CÂMARA DOS DEPUTADOS, s.d.). No caso da previdência social, sua contrarreforma "[...] vem sendo ensaiado desde 1989, que ganhou força a partir de 2016, e que passou a ser tocada em marcha acelerada desde o início de 2019" (FAGNANI, 2019, p. 28). Observa-se que o debate da contrarreforma da previdência prevalece na superficialidade e na desinformação da classe trabalhadora, pois as propostas não são discutidas em nenhum espaço democrático de participação popular, não há transparência do atual governo nessas ações. Ressalta-se que em um contexto de pandemia intensifica-se a dificuldade de articulação da classe trabalhadora para formar frentes de resistência a essa ofensiva. Objetivamente, a reforma na previdência impõe novas regras que atingem todos os direitos previstos nesta política, endurecendo o acesso e penalizando ainda mais a vida funcional da classe trabalhadora, além de condicionar o acesso a previdência privada para complementar a futura aposentadoria.

15 Está presente na própria Constituição Federal a previsibilidade da existência de um sistema complementar de saúde através da participação da iniciativa privada na gestão administrativa e na prestação dos serviços (a exemplo das Organizações de Saúde - OSs). Este modelo também tem chegado na educação pública e, no caso da educação superior, além do corte de verbas, projetos como o Future-se representam ameaça à autonomia universitária.
}

Temporalis, Brasília (DF), ano 21, n. 41, p. 87-101, jan./jun. 2021. | ISSN 2238-1856 
o desmonte do serviço público. O estrangulamento financeiro dessas políticas evidencia a ofensiva da lógica mercantilista na promoção do acesso ao direito à saúde e à educação, evidenciando a exclusão cotidiana da população mais pobre.

Diante disso, as contrarreformas e o capital pandêmico resultam numa onda de regressões sociais, em um contexto de cortes de orçamentos para a seguridade social e para a educação, com foco no desmonte desses direitos. Em relação à educação, que há anos vem resistindo à (1) tendência de privatização das universidades públicas - eis o projeto de lei Future-se $e^{16}$-, (2) precarização continuada agravada pela EC 95 (que congela os investimentos, prejudicando a aquisição de materiais, equipamentos e recursos humanos, sob a lógica da terceirização de serviços) e (3) ao corte das bolsas que financiam as pesquisas e as produções científicas, frente ao explícito desprezo da ciência e do conhecimento científico, na pandemia é submetida a deglutir a modalidade de ensino remoto, cuja ausência de construções horizontais com os sujeitos envolvidos no processo educativo reverbera a gravidade de sua introdução antidemocrática.

Não bastasse o avanço da educação à distância e o aligeiramento da formação profissional, especialmente na educação superior, a pandemia trouxe a modalidade do ensino remoto, o qual tem expandido a precarização do ensino, das condições de trabalho e do acesso ao conhecimento nos seus diferentes níveis, como pode ser observado a seguir.

\section{O ENSINO REMOTO NO CONTEXTO DE CAPITAL PANDÊMICO}

A pandemia e o ensino remoto estabeleceram uma relação intrínseca em face do isolamento social imposto pela quarentena, tornando esse modelo de ensino "a saída" para a suspensão das aulas presenciais, a partir da utilização de plataformas digitais de grandes corporações, como a Microsoft e o Google.

Juliana Melim e Lívia Moraes (2020), em seu texto Ensino remoto - porque dizemos não, esclarecem o que é essa modalidade de ensino e a distinguem da educação à distância (EaD), já consolidada e cada vez mais crescente, principalmente no âmbito da educação superior. As autoras inferem que a diferença entre essas modalidades de ensino é particular, pois o ensino remoto surgiu como uma "[...] resposta pragmática ao período estendido da quarentena [...]” (MELIM; MORAES, 2020, p. 1), e a modalidade de EaD “[...] está prevista no artigo 80 da Lei 9.394/1996 (Lei de Diretrizes e Bases da Educação Nacional) [...]" (MELIM; MORAES, 2020, p. 1) e possui um corpo de diretrizes para a sua efetivação, que incluem desde a previsão do acesso à tecnologia para assistir às aulas, até momentos presenciais como parte do processo formativo e avaliativo.

\footnotetext{
${ }^{16} \mathrm{O}$ projeto de lei Future-se está voltado para o financiamento privado das universidades públicas, num fomento à privatização. Jaime Giolo (2020) evidencia que tal projeto de lei busca inserir gestão externa para as universidades e institutos federais, no intento de atender aos interesses do mercado. $O$ autor destaca ainda que, "[...] as Ifes continuam como instituições do Estado, públicas e gratuitas, porém orientadas exclusivamente para o mercado, possibilitando às empresas apropriarem-se, de forma direta, da produção intelectual, científica, tecnológica e profissional das universidades e dos institutos, inclusive definindo o conteúdo do trabalho acadêmico" (GIOLO, 2020, p. 46).
} 
O que vem ocorrendo, atualmente, é um arranjo na metodologia de ensino na tentativa de transpor o ensino presencial para o remoto, marcado por um processo caótico que não possibilitou nenhuma preparação docente, discente e técnico-administrativa e, sequer, viabilizou políticas públicas para dar condições (1) de acesso às pessoas que estão à margem do contato com internet e computadores; (2) de sobrevivência para discentes que dependem diretamente da assistência estudantil; (3) de criar estratégias factíveis à formação requerida por cada área; dentre outros.

Nessa via, os impactos do ensino remoto para a educação superior são inúmeros, dentre os quais destacam-se:

1. O aumento do distanciamento entre ensino, pesquisa e extensão, especialmente no que se refere às atividades extensionistas, a qual

[... ] é parte do tripé que fundamenta a universidade pública e se define por ser uma atividade que estabelece uma relação dialógica entre a comunidade universitária e a sociedade externa, aproximando a universidade dos problemas reais da vida humana, inclusive em suas complexas interações com a natureza. Em tempos de pandemia, esta relação, mesmo que virtual, é essencial, já que ao mesmo tempo em que leva o conhecimento da comunidade acadêmica à sociedade, dela traz também seu conhecimento, contribuindo para que a ciência e a tecnologia tenham contato com os saberes socialmente produzidos e possam se apropriar da situação real da vida da população brasileira (COLETIVO DE ESTUDOS EM MARXISMO E EDUCAÇÃO, 2020, p. 11).

Em relação a esse impacto, Melim e Moraes (2020) argumentam que "[...] o[a] professor[a] torna-se, cada vez mais, um cumpridor de tarefas e um[a] acompanhador[a] de processos [...]" (MELIM; MORAES, 2020, p. 2) e afirmam ainda que o processo educativo não se restringe à sala de aula, pois há uma articulação indissociável entre ensino, pesquisa e extensão, que está relacionada com a comunicação entre universidade e comunidade. Há, também, a interação com o ambiente acadêmico no que se refere aos centros acadêmicos, teatros universitários, intercâmbio entre conhecimentos de disciplinas e cursos, além da dimensão cultural que o ambiente da universidade favorece, além da privação da autonomia no desenvolvimento de pesquisas pela falta de acesso às bibliotecas, laboratórios de pesquisa e salas de informática.

As autoras ressaltam que "[...] a utilização pragmática das novas tecnologias pode apenas mecanizar a educação, sofisticando métodos reprodutores de controle dos/as estudantes" (MELIM; MORAES, 2020, p. 2). Desse modo, "[...] as ferramentas em si não garantem a qualidade da formação, muito pelo contrário, ao eliminar a presença direta dos/as docentes, elimina também a possibilidade de construção do conhecimento de forma coletiva e democrática [...]" (MELIM; MORAES, 2020, p. 2) e fragiliza a dimensão didático-pedagógico do processo de ensino aprendizagem.

2. Inexistência de uma política de educação inclusiva para aqueles que não possuem condições de ter acesso à internet e as TIC's.

3 .

A pesquisa realizada pela Andifes e pelo Fonaprace, em 2018, sobre o perfil socioeconômico e cultural dos/as discentes de instituições de ensino superior, trazem dados preocupantes em um contexto de crise estrutural e ofensiva privatista sobre a educação pública. Esses dados mostraram que “[...] 40\% dos estudantes das 
universidades federais estavam desempregados e em busca de trabalho. Dentre os 30\% de estudantes que exerciam atividades remuneradas, $46 \%$ trabalhavam mais de 30 horas semanais e $44 \%$ em trabalhos precários" (COLETIVO DE ESTUDOS EM MARXISMO E EDUCAÇÃO, 2020, p. 13).

Entretanto, nos dias de hoje, essa alternativa é inaceitável, pois pressupõe deixar para trás uma parcela importante dos estudantes que, em virtude das condições de vida, não têm acesso com qualidade à internet, vivem em moradias que impossibilitam o mínimo de concentração para o desenvolvimento de estudos, muitos passam por privações econômicas severas, conformando um cotidiano psicossocial muito difícil. Desse modo, decretar aulas remotas é um gesto contra os estudantes das frações mais exploradas e expropriadas que ingressaram via cota, escola pública, e que são merecedoras das melhores esperanças de ampliar a democracia no país (COLETIVO DE ESTUDOS EM MARXISMO E EDUCAÇÃO, 2020, p. 07).

Esta dura realidade, em tempos de pandemia, impossibilita discentes de participarem da modalidade de ensino remoto. Não apenas a questão de classe e suas condições objetivas de sobrevivência se evidenciam como um impeditivo ao ensino remoto, mas também a questão de raça e gênero, as quais acentuam ainda mais o distanciamento desses sujeitos da formação em meio a nova modalidade.

Se atentarmos para o dado de que $54,6 \%$ dos estudantes das Universidades Federais são mulheres, ainda devemos considerar a sobrecarga de trabalho no cuidado da casa, dos filhos, dos idosos e dos parentes enfermos que, em uma sociedade machista, recai sobre as mulheres. Os altos índices de feminicídio e violência contra a mulher - que aumentaram cerca de $22 \%$ durante a pandemia as colocam em maiores condições de vulnerabilidade (COLETIVO DE ESTUDOS EM MARXISMO E EDUCAÇÃO, 2020, p. 13).

Dada essas circunstâncias, como considerar que esta modalidade de ensino seja inclusiva? De um modo geral, "[...] esta situação condena um expressivo número de estudantes a ficar para trás e a abandonar os seus estudos, em particular estudantes de baixa renda [...]” (COLETIVO DE ESTUDOS EM MARXISMO E EDUCAÇÃO, 2020, p. 14), um dado preocupante frente a perspectiva de universidade inclusiva e democrática.

4. Inserção de corporações capitalistas no interior da universidade pública.

Nesse cenário de sucateamento da política de educação e, consequentemente, da universidade pública, destaca-se o interesse do capital financeiro na modalidade de ensino remoto como uma forma de obter (mais) lucros. Diante do contexto de inserção destas corporações capitalistas nas universidades, reforça-se ainda mais a ameaça à privatização da universidade pública, ou seja, a perda processual do seu caráter público e gratuito.

Durante a pandemia, o Banco Mundial atua em coligação com grandes corporações para impulsionar o chamado 'mercado de soluções de gerenciamento da aprendizagem', que beneficiaria corporações como Amazon, Microsoft, Google e provedores de serviços como Moodle, Blackboard, Canvas, Zoom, Adobe Connect, Skype, Big Blue Button, EduMeet e diversos outros que são propagandeados nos relatórios do Banco Mundial (2020). Além deste rol de empresas aqui apresentado, o Brasil ainda conta com as soluções nacionais cuja intenção é, além de enriquecer setores privados, utilizá-los como ferramenta

Temporalis, Brasília (DF), ano 21, n. 41, p. 87-101, jan./jun. 2021. | ISSN 2238-1856 
para a guerra cultural por meio de um panfleto bolsonarista, visando encerrar qualquer possibilidade de formação crítica (COLETIVO DE ESTUDOS EM MARXISMO E EDUCAÇÃO, 2020, p. 15).

Dentro desse processo, destaca-se a mercadorização da educação, a superexploração da força de trabalho docente por meio destas plataformas, com a jornada de trabalho aumentada; o esforço para a adaptação de didáticas na modalidade remota; a precarização do ensino por meio de uma realidade virtual, no que se refere a perdas de conexões que sejam on-line ou por queda de energia; o exacerbado cansaço mental e visual por se tratar de uma jornada estendida em frente às telas do computador. Trata-se, portanto, de um projeto de educação privatista e excludente.

Melim e Moraes (2020) reforçam que essas condições intensificam a lógica do empresariado na educação, além de ser um espaço lucrativo para essas corporações, visto que "[...] a venda de pacotes tecnológicos, apostilas e recursos digitais aliadas à defesa de educação generalista e empreendedora e de esvaziamento do papel do professor compõem um projeto educacional" (MELIM; MORAES, 2020, p. 3). Segundo as autoras, tais circunstâncias reiteram a condição periférica do Brasil no contexto de capitalismo dependente, além de criar obstáculos à produção do pensamento crítico no processo educativo. Por fim, esta análise leva a pressupor "[...] que há um projeto não somente de acumulação de capital, mas também de controle ideológico" (MELIM; MORAES, 2020, p.3).

Na perspectiva de uma universidade voltada aos interesses de mercado instaura-se uma lógica essencialmente privatista e também excludente, além provocar uma mudança significativa na estrutura e autonomia das universidades públicas, na tentativa de desresponsabilização do Estado no que se refere o seu custeio.

Diante do exposto, a pandemia caracteriza um ensaio para a possibilidade de consolidação do ensino remoto como uma estratégia do capital pandêmico, na tentativa de acumulação de lucros e de consolidação de um "[...] projeto de educação do grande capital” (MELIN; MORAES, 2020, p. 4). É nessa via que as entidades organizativas do Serviço Social, no Brasil, vêm se posicionando e alertando acerca dos rebatimentos do ensino remoto na formação profissional, a seguir explicitado.

\section{O ENSINO REMOTO E O SERVIÇO SOCIAL: ENTRE A RESISTÊNCIA E AS NECESSIDADES DO MERCADO EM TEMPOS DE CAPITAL PANDÊMICO}

Não são novidades as inúmeras investidas do Ministério da Educação brasileiro, há anos, para a retirada da autonomia universitária, para o desfinaciamento da universidade pública, para a restrição dos concursos públicos à educação e para o fomento e estímulo ao ensino privado, via grandes corporações educacionais.

É nesse contexto que a educação pública superior brasileira vem sendo duramente golpeada por meio de um processo intensificado de mercantilização, desestruturação, privatização e perda de autonomia, que, entre outras coisas, tem se expressado nos sucessivos cortes orçamentários que somam, desde 2015, mais de 6 bilhões de reais (FARAGE, 2021, p. 49).

Temporalis, Brasília (DF), ano 21, n. 41, p. 87-101, jan./jun. 2021. | ISSN 2238-1856 
Ademais, no bojo da pandemia, esses interesses vêm adquirindo novo tônus, porque associadas às medidas e necessidades de isolamento e distanciamento social, ganham espaço físico e regulamentar, soando como respostas do MEC às "novas necessidades pandêmicas" no campo da educação. O ensino remoto é o seu exemplo clássico. Indispensável rememorar que desde a aprovação da Lei de Diretrizes e Bases da Educação Nacional (LDB), de 1996 - que aprova a oferta do ensino na modalidade à distância - a educação brasileira vem sendo impactada pela oferta desmensurada do ensino nessa modalidade, sem regulamentação própria e critérios para a garantia das condições mínimas necessárias para assegurar a qualidade da formação profissional, nas diferentes áreas do conhecimento. Nessa via, pelas investidas governamentais da época até os tempos hodiernos, registra-se a constituição de diferentes instituições de ensino especializadas na modalidade; a criação de monopólios, com os conglomerados educacionais, que sob viés comercial e lucrativo, tem na modalidade uma via aberta de mercadorização do ensino ${ }^{17}$; e o discurso difuso dos governos brasileiros pelo desmonte da universidade pública, como lócus de gasto público e pouca eficiência, se comparado às instituições de natureza privada (seja na modalidade presencial, seja na modalidade à distância).

O atual governo, não destoa de tais tendências. Aliás, embebido de anticiência, prolifera suas investidas em face de "[...] uma nova normalidade que camufla o crescente movimento de desqualificação da Educação Superior" (ASSOCIAÇÃO BRASILEIRA DE ENSINO E PESQUISA EM SERVIÇO SOCIAL, 2020, p. 2). É nesse cenário que as entidades organizativas da categoria, no Serviço Social, vêm se posicionando em face da Portaria Ministerial do Ministério da Educação MEC $n^{\circ} 343$, de 17 de março de 2020, que autorizou, em caráter excepcional, a realização do ensino presencial por intermédio da utilização de meios e tecnologias de informação e comunicação e que, por sua vez, dada a ausência dos mecanismos concretos para sua viabilização - leia-se políticas públicas -, vem causando impactos deletérios para a educação, aqui em destaque a superior ${ }^{18}$.

\begin{abstract}
Com diferentes nomenclaturas e narrativas, as propostas de Ensino Remoto Emergencial (ERE) apresentadas nas universidades do Brasil possuem visíveis fragilidades, em suas bases legais e em seus pressupostos pedagógicos e de planejamento das atividades de ensino, acentuando as tendências à improvisação e à desqualificação do processo, responsabilizando individualmente a docentes e discentes por garantir o processo de aprendizagem (ASSOCIAÇÃO BRASILEIRA DE ENSINO E PESQUISA EM SERVIÇO SOCIAL et al., 2020, p. 2).
\end{abstract}

O ensino remoto, potencializado pela pandemia - vale lembrar que a modalidade do ensino virtual e o home office não são invenções pandêmicas - guardadas as diferenças locais, regionais e institucionais, vem sendo utilizado de maneira desordenada, com o

\footnotetext{
${ }^{17}$ Para exemplificar, o grupo Kroton, maior conglomerado educacional até 2019, vira Cogna e se divide em quatro para atrair diferentes investidores. Explicitamente, a educação compondo a bolsa de valores, inserida no âmbito do capital financeiro.

${ }^{18}$ Não se pode deixar de referir o quanto o ensino básico também vem sendo prejudicado, uma vez que em muitas regiões, como é o caso do Distrito Federal, as aulas desde as normativas de isolamento e distanciamento social (março/2020) não foram retomadas e não há um planejamento programático, com as medidas de proteção adequadas, para o retorno das aulas. Assim, enquanto discentes permanecessem em casa com atividades pontuais, se amplia o distanciamento educacional em relação às escolas particulares, as quais retomaram suas atividades ainda em setembro de 2020.
}

Temporalis, Brasília (DF), ano 21, n. 41, p. 87-101, jan./jun. 2021. | ISSN 2238-1856 
intento de cumprir orientações estabelecidas pelo órgão educacional regulador (MEC). Destaca-se, assim, que a crítica não é em relação ao ensino remoto em si, pois entende-se em determinadas regiões, cujo distanciamento geográfico é dificultado ou a oferta presencial pública ou privada é limitada, o ensino por meio das tecnologias de informação e comunicação torna-se uma possibilidade - não se quer dizer que a única - mas a forma obrigatória e autoritária de deglutição, sem qualquer discussão ampliada sobre sua introdução. Quer-se dizer que a crítica é em relação àquilo que está nas entrelinhas, que está oculto e que permeia um movimento (não recente) de abertura desordenada à modalidade não presencial e, no âmbito da universidade pública, sua progressiva privatização ${ }^{19}$.

Nessa via, as entidades organizativas da categoria - leia-se Associação Brasileira de Ensino e Pesquisa em Serviço Social (ABEPSS), Conselho Federal de Serviço Social (CFESS) e Executiva Nacional dos Estudantes de Serviço Social (ENESSO) - vêm se posicionando de maneira crítica acerca de tal questão, ao pontuar seus principais nós. Em nota, as referidas entidades, em conjunto com o Conselho Regional de Serviço Social do Rio de Janeiro, ao abordar o ensino remoto, enfatizam que

[...] é preciso de partida considerar as profundas mudanças econômicas e sociais desencadeadas pela pandemia, com fortes impactos na vida de docentes, discentes, servidoras/es técnico-administrativas/os e trabalhadoras/es terceirizadas/os. O debate das condições para o ERE não se reduz ao acesso à rede de internet e à disponibilidade de telefone celular e/ou demais equipamentos. É preciso considerar todos os efeitos da desigualdade social combinados à crise sanitária e econômica, tais como: o agravamento da precarização laboral (uberização, informalização e terceirização); do desemprego e/ou da redução de salários, que têm causado instabilidade social e psicológica para a imensa maioria da sociedade (ASSOCIAÇÃO BRASILEIRA DE ENSINO E PESQUISA EM SERVIÇO SOCIAL et al., 2020, p. 03).

Na contramão do negacionismo do real, entende-se a excepcionalidade histórica mundial e a necessidade de problematizar criticamente os impactos deletérios que circundam as orientações do Ministério da Educação em relação ao ensino remoto, quais sejam: (1) a prática da modalidade remota de maneira forçosa para a manutenção do trabalho; (2) o risco eminente, em tempos de ameaças à liberdade de expressão política, em face da ausência de aparato legal do uso de imagens, vídeo-aulas e materiais didáticos, dando espaço para seu uso indevido, para práticas autoritárias e para o ataque à liberdade de cátedra; (3) a desqualificação da ciência e da pesquisa, os quais são contributos fulcrais da universidade; (4) a ampliação de um projeto privatista de educação, seguindo orientações dos organismos internacionais, sem análise aprimorada da realidade nacional, das suas desigualdades estruturantes, da diversidade regional, da continentalidade do país; (5) o risco de aprofundamento das desigualdades sociais, mediante a ausência de políticas públicas que criem mecanismos para garantia do acompanhamento, de maneira satisfatória, da modalidade remota (ASSOCIAÇÃO BRASILEIRA DE ENSINO E PESQUISA

\footnotetext{
${ }^{19}$ Em publicação realizada em 2017, o Banco Mundial alertava o governo brasileiro sobre o que denominam de altos custos de manutenção das universidades públicas, em comparação às privadas, evidenciado que nas primeiras o percentual é aproximadamente 200\% maior (BANCO MUNDIAL, 2017). Todavia, curiosamente a pesquisa se limita ao critério monetário, sem debruçar-se nas informações qualitativas da formação; no perfil socioeconômico discente; na formação/qualificação docente; na interlocução entre ensino, pesquisa e extensão; na formação científica; nos programas voltados à permanência na universidade, entre tantos outros que se poderia evidenciar.
}

Temporalis, Brasília (DF), ano 21, n. 41, p. 87-101, jan./jun. 2021. | ISSN 2238-1856 
EM SERVIÇO SOCIAL et al., 2020); (6) a sobrecarga do trabalho docente, não apenas pela necessidade imediata de apropriação do uso das tecnologias, mas pelo acúmulo de atividades em frente à tela, de aulas síncronas e assíncronas, de reuniões infindáveis, de orientações, de atividades em grupos de pesquisa, de preparação de material pedagógico e produção do conhecimento, dentre tantos outros; (7) a inexistência de apoio pedagógico e tecnológico, responsabilizando docentes e discentes pelo processo de ensino-aprendizagem remoto, sem intermediação institucional e ministerial em relação ao enfrentamento das dificuldades e limitadores intrínsecos; (8) a adequação do trabalho docente ao processo de reestruturação produtiva e precarização do mundo do trabalho que esvazia o sentido do trabalho de professores/as universitários (FARAGE, 2021); (9) a ausência de diálogo com as categorias envolvidas no processo educativo, sejam sindicatos, departamentos/colegiados ou diretórios de estudantes, demonstrando desrespeito às instâncias democráticas; e, ainda (10) o esvaziamento do processo pedagógico mediante a organização de aulas remotas.

Em face dos elementos apontados e das lutas que a educação brasileira vem atravessando, a ABEPSS (2020) manifestou seu posicionamento explicitamente, indicando a educação como direito e não como negócio; a defesa do trabalho intelectual, docente e discente, com autonomia e condições de trabalho; e a autonomia universitária com financiamento público.

Nessa via, não se pode vendar os olhos sobre essa modalidade de ensino, “[...] considerando os seus pressupostos científicos e metodológicos, bem como as reflexões sobre sua dimensão política e jurídica que envolve o trabalho profissional em todas as suas dimensões [...]" (ASSOCIAÇÃO BRASILEIRA DE ENSINO E PESQUISA EM SERVIÇO SOCIAL et al., 2020, p. 6), e, tampouco, deixar de construir respostas para as demandas de uma crise mundial (sanitária) inédita. Quiçá, a crise humanitária mais letal dos nossos tempos. Trata-se, pois, de considerar as condições objetivas para o uso do ensino remoto e constituir políticas públicas que não sejam epidérmicas ${ }^{20}$, mas que levem em conta os indicadores concretos da realidade, com vistas ao seu enfrentamento.

\section{CONSIDERAÇÕES FINAIS}

A atual conjuntura está sendo um laboratório para um mundo pós-pandemia ${ }^{21}$, com seus mecanismos de intensificação da superexploração da força de trabalho, a exemplo das práticas de home Office, EaD (ensino à distância), teletrabalho, desenvolvimento e dependência das tecnologias de informação e comunicação (TIC), inteligência artificial, etc. Estas modalidades levam à individualização do trabalho, ao distanciamento da organização social e sindical, à tendência de supressão de direitos e à intensificação da desigualdade social e racial. Assim, tecem os caminhos para a barbárie social, em que a classe trabalhadora é a maior prejudicada e penalizada pelo modo de produção capitalista, agora em sua face de capital pandêmico. Antunes (2020) ressalta que a pandemia não está desconectada do sistema sociometabólico do capital e que não se

\footnotetext{
${ }^{20}$ As quais tem "[...] seu fundamento na radicalização do projeto privatista de educação no país" ABEPSS (2020, p. 4).

${ }^{21}$ Evidentemente o avanço das TIC's e do trabalho digital é uma das principais características do póspandemia.
}

Temporalis, Brasília (DF), ano 21, n. 41, p. 87-101, jan./jun. 2021. | ISSN 2238-1856 
trata de um fenômeno natural, sua processualidade resulta na destruição, tanto da natureza, quanto da própria humanidade.

Diante do contexto de capital pandêmico, percebe-se que os efeitos do ensino remoto são nefastos para a política de educação, colocando em xeque a qualidade da formação de base e profissional, por isso não devem ser naturalizados, mas precisam ser debatidos e dialogados. Os limites que o ensino remoto coloca para a educação ecoam questionamentos como "por quanto tempo vai durar?" "Quais os impactos para as instituições de ensino públicas e para os sujeitos?”

Nesse sentido, o Serviço Social, através de suas entidades organizativas, manifesta posicionamento político crítico em relação as medidas impostas à educação que ampliam o projeto burguês de privatização das universidades, fragilizam o ensino e a formação profissional de qualidade e afetam significativamente a vida dos sujeitos envolvidos no processo de ensino remoto, reafirmando a sempre atual necessidade de luta contra a barbárie e a resistência pela garantia da vida e dos direitos.

\section{REFERÊNCIAS}

ASSOCIAÇÃO BRASILEIRA DE ENSINO E PESQUISA EM SERVIÇO SOCIAL. Nota sobre trabalho remoto em tempos de pandemia: em defesa da graduação e pós-graduação em Serviço Social. Temporalis, Brasília (DF), ano 20, n. 39, p. 279-284, jan./jun. 2020.

ASSOCIAÇÃO BRASILEIRA DE ENSINO E PESQUISA EM SERVIÇO SOCIAL et al. Trabalho e ensino remoto emergencial. Brasília (DF), 2020. Disponível em:

http://www.cfess.org.br/arquivos/1NotaForumNacional2020.pdf. Acesso em: 11 mar. 2021.

ANTUNES, Ricardo. Coronavírus: o trabalho sob fogo cruzado. São Paulo: Boitempo, 2020. Ebook.

BANCO MUNDIAL. Um ajuste justo: análise da eficiência e equidade do gasto público no Brasil. Grupo Banco Mundial, 2017.

CÂMARA DOS DEPUTADOS. Congresso Nacional promulga Emenda Constitucional que garante volta do auxílio emergencial. Notícias, Brasília (DF), [s.d.]. Disponível em: https://www.camara.leg.br/noticias/736147-congresso-promulga-emenda-constitucionalque-garante-volta-do-auxilio-emergencial/. Acesso em: 12 mar. 2021.

\section{COLETIVO DE ESTUDOS EM MARXISMO E EDUCAÇÃO (COLEMARX). Universidades}

Públicas e aulas remotas: nenhum estudante pode ser excluído. Rio de Janeiro: UFRJ, 2020.

DINO, Flavio. Coronavírus e fascismo: Patologias que desafiam o Brasil. In: TOSTES, Anjuli; MELO FILHO, Hugo (orgs). Quarentena: reflexões sobre a pandemia e depois. Bauru /SP: Projeto Editorial Praxis; canal6 editora, 2020, p. 65-69.

FAGNANI, Eduardo. Previdência social: o debate desonesto. Subsídios para a ação social e parlamentar: pontos inaceitáveis da reforma de Bolsonaro. São Paulo: Contracorrente, 2019 .

Temporalis, Brasília (DF), ano 21, n. 41, p. 87-101, jan./jun. 2021. | ISSN 2238-1856 
FARAGE, Eblin. Educação superior em tempos de retrocessos e os impactos na formação profissional do Serviço Social. Serviço Social e Sociedade, São Paulo, n. 140, p. 48-65, jan./abr. 2021.

GIOLO, Jaime. O Future-se sem futuro. In: COSTA, Jaime; LEHER, Roberto; SGUISSARDI, Vademar. Future-se: ataques à autonomia das instituições federais de educação superior e sua sujeição ao mercado. São Carlos/SP: Diagrama Editorial, 2020, p. 15-101. E-book.

INSTITUTO BRASILEIRO DE GEOGRAFIA E ESTATÍSTICA (IBGE). Desemprego. Brasília (DF), [2021]. Disponível em: https://www.ibge.gov.br/explica/desemprego.php. Acesso em: 19 jun. 2021.

HARVEY, David. Política anticapitalista em tempos de COVID-19. In: DAVIS, Mike, et al. Coronavírus e a luta de classes. Teresina; Fortaleza: Terra sem Amos, 2020, p. 13-24.

LOWY, Michel. "Gripezinha” o neofascista Bolsonaro diante da epidemia. In: TOSTES, Anjuli; MELO FILHO, Hugo (orgs). Quarentena: reflexões sobre a pandemia e depois. Bauru /SP: Projeto Editorial Praxis; canal6 editora, 2020, p.147-151.

MELIM, Juliana Iglesias; MORAES, Lívia de Cássia Godoi Moraes. Ensino remoto: porque dizemos não. Texto para o debate. Vitória/ES: UFES, 2020.

Laryssa Danielly Silva Fernandes Trabalhou na redação do artigo.

Assistente Social (UFAL). Mestranda do Programa de Pós-Graduação em Política Social (SER/UnB). Membro do Grupo de Estudos e Pesquisas sobre Fundamentos do Serviço Social e América Latina (GFAL).

Marileia Goin Trabalhou na redação do artigo.

Assistente Social. Mestre e Doutora em Serviço Social. Líder do Grupo de Estudos e Pesquisas sobre Fundamentos do Serviço Social e América Latina (GFAL). Professora da graduação e da pós-graduação do Departamento de Serviço Social da Universidade de Brasília (UnB).

Islânia Lima da Rocha Trabalhou na redação do artigo.

Assistente Social. Mestra em Serviço Social (PPGSS/UFAL). Doutoranda do Programa de Pós-graduação em Serviço Social da Faculdade de Serviço Social (FSSO/UFAL). Membro do Grupo de Pesquisa sobre Reprodução Social. Professora do curso de Serviço Social da Faculdade de Serviço Social (FSSO/UFAL). 